\title{
Viabilidade econômico-financeira de sistemas de produção de cordeiros não desmamados em pastagem com suplementação em cocho ou pasto privativo
}

\author{
Financial-economic feasibility of not-weaned grazing lambs supplemented in privative \\ trough or with pasture
}

\author{
STIVARI, Thayla Sara Soares ${ }^{1 *}$; MONTEIRO, Alda Lúcia Gomes ${ }^{2}$; GAMEIRO, \\ Augusto Hauber ${ }^{1}$; CHEN, Rafael Felice Fan²; SILVA, Cláudio José Araújo da²; DE \\ PAULA, Edson Ferraz Evaristo ${ }^{3}$; KULIK, Carlos Henrique ${ }^{2}$, PRADO, Odilei Rogério ${ }^{2}$
}

\footnotetext{
${ }^{1}$ Universidade de São Paulo, Faculdade de Medicina Veterinária e Zootecnia, Programa de PósGraduação em Nutrição e Produção Animal. Pirassununga, São Paulo, Brasil.

${ }^{2}$ Universidade Federal do Paraná, Departamento de Zootecnia, Programa de Pós-Graduação em Ciências Veterinárias, Curitiba, Paraná, Brasil.

${ }^{3}$ Prefeitura Municipal de Curitiba, Departamento de Pesquisa e Conservação da Fauna, Curitiba, Paraná, Brasil.

*Endereço para correspondência: thayla.stivari@gmail.com
}

\section{RESUMO}

Objetivou-se analisar os custos e a rentabilidade de sistemas de produção de ovinos em pastagem sob três estratégias de suplementação de cordeiros lactentes: (1) creep grazing de trevo branco; (2) creep feeding; e (3) sem suplementação. Utilizaram-se dois métodos de análise financeira: análise anual (de curto prazo) e de fluxo de caixa (de longo prazo). Os custos foram segmentados em variáveis, fixos, operacionais e totais. $\mathrm{O}$ fator de produção que exerceu maior influência no custo variável da produção foi a alimentação, e no custo total foi o custo de oportunidade do capital imobilizado. O sistema com creep grazing não apresentou resultados econômico-financeiros superiores aos com creep feeding.

Palavras-chave: creep feeding, creep grazing, custo de produção, ovinocultura, rentabilidade

\section{SUMMARY}

The objective was to analyze production costs and profitability of grazing sheep productions systems under three strategies of lamb's supplementation: (1) white clover on creep grazing; (2) creep feeding; and (3) not supplemented. Two methods of financial analyses where used: annual (short term) and cash flow (long term). Costs were classified into variable, fixed, operational and total. Results showed that feeding and opportunity cost over investment was the most important production factors at variable and total costs, respectively. System with creep grazing supplementation did not show greater economic financial results over creep feeding supplementation system.

Keywords: creep feeding, creep grazing, production costs, profitability, sheep

\section{INTRODUÇÃO}

As estimativas dos custos de produção e o estudo da viabilidade econômica são fundamentais para as atividades pecuárias e a caracterização adequada de um sistema de produção é o primeiro passo para o início da avaliação econômica. Aliada às vastas áreas de pastagens, novas estratégias de produção de ovinos a pasto vem sendo testadas e aprimoradas a cada ano. Dentre as estratégias destaca-se o manejo na fase de terminação com a utilização de suplementos alimentares exclusivos para cordeiros. 
A alimentação exclusiva e diferenciada das crias pode ser realizada para melhorar o ganho de peso dos cordeiros e diminuir o tempo ao abate, aproveitando a fase de maior eficiência alimentar dos animais e resultar em carne de melhor qualidade (QUADROS, 2005). Nesse contexto, existem dois principais modelos: os que utilizam de alimentos concentrados (creep feeding) e os que utilizam de forrageiras de melhor valor nutritivo (creep grazing). $\mathrm{O}$ fornecimento de alimento concentrado a base de grãos tem sido utilizadas com sucesso, uma vez que são compostas por ingredientes com elevados teores de proteínas e/ou carboidratos (SNIFFEN et al., 1992). Entretanto, os dispêndios com concentrado podem elevar o custo de produção, tornando a rentabilidade inferior.

Em contrapartida, no sistema de produção em pasto privativo ou creep grazing são utilizadas forragens de alta qualidade nutricional, providas em campos adjacentes às pastagens onde as mães pastejam, sendo permitida apenas a entrada dos cordeiros. Pesquisas realizadas com ovinos no Instituto Nacional de Investigación Agrária (INIA), do Uruguai, por Banchero \& Montossi (1995) utilizando dessa técnica observaram que, na maioria das vezes, o ganho de peso dos cordeiros em creep grazing, foi superior em relação ao sistema em creep feeding. Os estudos no Brasil ainda são recentes. Silva (2010) aponta não haver diferença de ganho médio diário quando comparado os dois sistemas de suplementação. Com isso, devido ao alto do valor da terra no Brasil e a necessidade de maiores áreas de pastagem nos sistemas com suplementação a pasto, faz-se necessário a realização de estudos de viabilidade econômica para que se possa recomendar o uso dos sistemas em creep grazing.

O objetivo deste trabalho foi analisar a formação dos custos e a viabilidade econômico-financeira de sistemas de produção de ovinos em pastagem com a utilização de suplementação em cochos ou pastos privativos durante a fase de terminação de cordeiros lactentes.

\section{MATERIAIS E MÉTODOS}

Esta pesquisa foi desenvolvida a partir de dados obtidos em experimento realizado entre setembro e dezembro de 2007 na Fazenda Experimental do Canguiri, da Universidade Federal do Paraná (UFPR), com o rebanho ovino Suffolk do Laboratório de Produção e Pesquisa em Ovinos e Caprinos (LAPOC), em Pinhais/PR. Os sistemas estudados contemplaram a utilização de pastagem de azevém anual (Lolium multiflorum Lam.) sobressemeada em pastagem perene de Tifton-85 (Cynodon sp.), como pastagem principal, e o uso das estratégias de suplementação dos cordeiros: (1) creep grazing de trevo branco (Trifolium repens) ad libitum; (2) creep feeding com alimento concentrado a $2 \%$ do peso corporal (PC) por dia; e (3) sem suplementação. Ribeiro (2010) avaliou o desempenho zootécnico e as características da carcaça de cordeiros e desse trabalho foram utilizados os dados de peso vivo inicial (PVI) e final (PVF), ganho médio diário (GMD), idade de abate, rendimento e peso médio da carcaça. Utilizou-se ainda os dados produtivos da pastagem de Silva (2010) que se referem ao mesmo experimento de Ribeiro (2010). Esses dados são apresentados na Tabela 1. A partir desses coeficientes técnicos desenvolveu-se a análise econômico- 
financeira dos referidos sistemas. Enfoques de curto e longo prazo foram contemplados. As análises de curto prazo $(\mathrm{CP})$ compreenderam o cálculo de margem bruta (MB), margem líquida (ML), resultado econômico (RE), taxa de retorno do patrimônio líquido (TRPL) e o ponto de equilíbrio (PE) para o período de um ano, representativo de um ciclo produtivo. Para as análises de longo prazo, elaborou-se fluxo de caixa mensal para o horizonte de 10 anos, totalizando 120 meses, a partir do qual os indicadores de valor presente líquido (VPL), taxa interna de retorno (TIR) e relação benefício/custo $(B / C)$, foram calculados.

Tabela 1. Dados produtivos do rebanho e da pastagem de azevém anual, entre setembro a dezembro de 2007, dos sistemas de terminação de cordeiros e área necessária para suporte de 300 matrizes, seus respectivos cordeiros lactentes, reprodutores e rufiões, para oferta de $12 \%$ de MS por Kg de PV

\begin{tabular}{lccc}
\hline \multirow{2}{*}{ Dados produtivos do rebanho } & \multicolumn{3}{c}{ Sistemas de terminação } \\
\cline { 2 - 4 } & Creep grazing & Creep feeding & Sem suplementação \\
\hline Peso vivo inicial cordeiros (kg) & $17,33 \pm 3,07$ & $16,96 \pm 3,86$ & $18,41 \pm 2,63$ \\
Peso vivo final cordeiros (kg) & $33,17 \pm 1,31$ & $33,04 \pm 0,29$ & $34,04 \pm 1,34$ \\
Ganho médio diário - GMD (g) & $274^{\mathrm{a}}$ & $307^{\mathrm{a}}$ & $204^{\mathrm{b}}$ \\
Idade de abate dos cordeiros (dias) & $94^{\mathrm{a}}$ & $90^{\mathrm{a}}$ & $106^{\mathrm{a}}$ \\
Rendimento de carcaça quente (\%) & $48,67^{\mathrm{a}} \pm 3,43$ & $47,78^{\mathrm{a}} \pm 1,98$ & $47,47^{\mathrm{a}} \pm 4,46$ \\
Peso médio da carcaça quente (kg) & $16,16^{\mathrm{a}} \pm 1,52$ & $15,71^{\mathrm{a}} \pm 0,65$ & $16,2^{\mathrm{a}} \pm 2,11$ \\
\hline Dados produtivos da pastagem* & & & 2393,5 \\
\hline Carga animal (kg PV/ha) & 2255,5 & 2276,3 & 77,9 \\
Taxa de acúmulo (kg de MS/ha) & 83,9 & 89,2 & 4394,7 \\
Massa de forragem (kg de MS/ha) & 3922,6 & 3863,4 & 0,6 \\
Área pasto principal (ha) & 17,2 & 17,1 & - \\
Área para machos (ha) & 0,6 & - & 16,8 \\
Área de trevo branco (ha) & 9,0 & 17,7 & \\
Área total (ha)** & 26,8 & & \\
*Avaliações de pastagem realizadas a cada 21 dias (SILVA, 2010). & \\
**Área total = área de pastagens, reserva legal, reserva permanente e área ocupada por benfeitorias. \\
Médias seguidas de letras minúsculas distintas nas linhas apresentaram diferença significativa pelo teste \\
de Tukey a 5\% de probabilidade. \\
Fonte: Ribeiro (2010); adaptado de Silva (2010) e dados da pesquisa.
\end{tabular}

De modo a delinear a propriedade comercial representativa adotou-se $\mathrm{o}$ número de 300 matrizes, pré-fixado, tendo o excedente considerado como vendido. Estipulou-se a proporção de um reprodutor e rufião para cada 50 matrizes. De modo a representar a dinâmica do rebanho comercial. Os coeficientes zootécnicos médios considerados foram obtidos a partir dos registros do LAPOC para o ano de 2007. São eles: $88 \%$ de taxa de fertilidade, $140 \%$ de taxa de natalidade,
1,6 de prolificidade, $4 \%$ de mortalidade de animais adultos, 9\% de mortalidade neonatal de cordeiros, $13 \%$ descarte anual de ovelhas, descarte de um reprodutor e um rufião por ano. Esses coeficientes foram adotados para os três sistemas. Ademais se considerou não haver morte de cordeiros durante o período de terminação. Esta premissa está alinhada com os resultados do experimento realizado por Ribeiro (2010) e Silva (2010). 
Para os três sistemas os animais permaneceriam em pastagem durante $o$ ano todo, em pastejo contínuo com oferta de $12 \%$ do PC dos animais em matéria verde de forragem.dia ${ }^{-1}$. No período reprodutivo foi realizado flushing, 15 dias pré-monta com $300 \mathrm{~g}$ de concentrado ( $16 \%$ de proteína bruta, PB; 74\% de nutrientes digestíveis totais, NDT na matéria seca, MS) por animal/dia. Nos 15 dias pré e pósparição das ovelhas gestantes foi ofertado o mesmo concentrado acrescido de volumoso, na oferta de $800 \mathrm{~g}$ de concentrado mais $2,4 \mathrm{~kg}$ de silagem de milho por ovelha.dia ${ }^{-1}$. Especificamente no sistema 1 (creep grazing) a suplementação com trevo branco apresentou composição química de $24,1 \%$ de PB e $75,4 \%$ de NDT na MS. No sistema 2 (creep feeding) o concentrado constituído de: farelo de soja $(40 \%)$, farelo de milho (40\%), farelo de trigo $(15 \%)$, suplemento mineral $(2 \%)$, calcário $(2,5 \%)$ e sal comum (0,5\%); perfazendo $24,7 \% \mathrm{~PB}$; $89,2 \%$ NDT na MS.

Todos os preços utilizados nos cálculos foram os médios praticados no ano de
2011, obtidos por consulta ao banco de dados de preços pagos pelo produtor da SEAB-PR (2011). Os dados faltantes foram levantados junto aos fornecedores da região de Curitiba. Todos os valores foram deflacionados para o mês de agosto de 2011 utilizando o Índice Nacional de Preços ao Consumidor (INPC), (IBGE/INPC, 2011). O custo da aquisição de silagem de milho pronta para consumo foi de $\mathrm{R} \$ 0,43 / \mathrm{kg}$. As despesas com o manejo e formação do pasto foram contabilizadas de acordo com o modelo proposto pela AgraFNP (2010).

Para cálculo dos custos fixos elaborouse inventário da terra e das benfeitorias necessárias para os sistemas com determinação do preço do bem novo e da vida útil. Estipulou-se a área necessária para suporte do rebanho e manutenção da oferta de forragem de acordo com os dados produtivos da pastagem no período de 2007 para cada sistema (Tabela 1). A fórmula utilizada para o cálculo de área (HERINGER \& CARVALHO, 2002), foi:

$\mathrm{CA}=\left[\left(\right.\right.$ Taxa de acúmulo MS $\times \mathrm{n}^{\circ}$ de dias $)+$ massa de forragem $] / \mathrm{n}^{\circ}$ de dias $\times 100$ Oferta pretendida

Para o creep grazing manteve-se a proporção utilizada por Silva (2010) de 2:1 (pastagem principal/creep grazing), perfazendo nove hectares de pastagem dividida em piquetes anexos aos piquetes principais das matrizes. Atribuiu-se $20 \%$ da área total como reserva legal, $5 \%$ da área total como reserva permanente e 0,03 hectares ocupados com benfeitorias.

No inventário dos três sistemas seguiuse o modelo adotado pelo LAPOC onde foram computados um depósito de $50 \mathrm{~m}^{2}$ e aprisco de $240 \mathrm{~m}^{2}$, cercas teladas no perímetro dos piquetes e, entre piquetes, cercas elétricas. As máquinas foram: uma roçadeira manual, uma balança para pesagem dos animais, um misturador de ração e uma geladeira. Somou-se o valor de todas as máquinas e equipamentos e adicionou-se 5\% sobre esse valor para outros equipamentos e ferramentas. Para cálculo de conservação e reparos consideraram-se $2 \%$ do valor de cada benfeitoria por ano, com exceção das cercas, cuja taxa foi de $15 \%$ ao ano e para máquinas e equipamentos $10 \%$ do valor do bem novo. A depreciação foi obtida pelo Método Linear 
(HOFFMANN et al., 1981), onde é igual ao valor do bem novo menos o valor final do bem, divididos pela vida útil. Como valor final, adotou-se 10\% do valor inicial para máquinas e equipamentos e $20 \%$ para as benfeitorias, exceto outros equipamentos e cercas, cujos valores finais foram zero. A vida útil foi de 30 anos para aprisco e depósito, 15 anos para as cercas, bebedouros, comedouros, saleiro, geladeira e misturador de ração, e cinco anos para roçadeira e balança. Esses indicadores foram estipulados a partir da experiência histórica do LAPOC.

Os custos com medicamentos foram estimados com base no consumo do LAPOC. A vacinação e seu reforço contra Clostridioses foram contabilizadas e os custos com antiparasitários estimados com base no que foi realizado durante $\mathrm{o}$ experimento.

O custo mensal com assistência técnica foi de $60 \%$ do salário mínimo regional do Estado do Paraná (R\$ 708,14). A mão de obra foi a de um funcionário com um salário mínimo regional mais encargos trabalhistas de $45,59 \%$ sobre o total (CONAB, 2010). Os impostos e taxas considerados sobre a receita total foram: INSS na alíquota de $2,3 \%$ das receitas e $1 \%$ para taxas diversas (CANZIANI, 2005). O ITR não foi computado porque a propriedade possui área menor que 30 ha, sendo, portanto, isento à cobrança (BRASIL, 1997). O consumo de energia elétrica foi estimado para cada sistema de acordo com a necessidade de produção de alimento concentrado, a $\mathrm{R} \$ 0,20$ o $\mathrm{kWh}$. As despesas gerais corresponderam a $1 \%$ do custo variável, exceto assistência técnica, impostos e taxas (SISTEMA FAEP, 2005).

Para estimativa do capital investido considerou-se o valor total investido em terras, benfeitorias, máquinas e equipamentos e rebanho a partir do inventário elaborado. Para estabelecer o custo de oportunidade do capital imobilizado, optou-se por utilizar a taxa de juros de mercado em 0,5\% a.m. (valor referencial historicamente praticado pela Caderneta de Poupança). Como custo de oportunidade do capital de giro considerou-se a taxa nominal de juros praticada pela Caixa Econômica Federal a fundo de empréstimo de crédito $(1,89 \%$ a.m.) sobre as despesas diretas da produção. Os preços de venda foram os praticados na região em agosto de 2011, a saber: R\$ 5,46 o quilo de cordeiro vivo terminado, $\mathrm{R} \$$ 3,80 o quilo para os animais de descarte (ovelhas e rufião), R $\$ 400,00$ o macho jovem com um ano de vida, $\mathrm{R} \$ 300,00$ a fêmea jovem com sete meses de vida e $\mathrm{R} \$ 1.388,00$ o reprodutor adulto.

Com todos os itens que compõem o custo de produção, os mesmos foram organizados segundo a metodologia proposta pela CONAB (2010) em: custo variável $(\mathrm{CV})$, custo fixo $(\mathrm{CF})$, custo operacional total (COT) e custo total de produção (CT). Sendo: $\mathrm{CV}$ a soma das despesas diretas da produção; $\mathrm{CF}$, depreciação e mão de obra permanente; $\quad \mathrm{COT}=\mathrm{CV}+\mathrm{CF}$; $\quad \mathrm{e}$ $\mathrm{CT}=\mathrm{COT}+$ custo de oportunidade do capital imobilizado. A margem bruta (MB) foi: receita total $\mathrm{RT}-\mathrm{CV}$; a margem líquida: $\mathrm{ML}=\mathrm{RT}-\mathrm{COT}$; $\mathrm{RE}=\mathrm{RT}-\mathrm{CT}$. A TRPL foi calculada dividindo o RE pelo investimento total subtraído o capital de giro (BARATA, 2003). O ponto de equilíbrio: $\mathrm{PE}=\mathrm{CT} / \mathrm{RT}$, e definindo-se o percentual da receita total que cobre o custo total de produção, no qual não há lucro nem prejuízo (LOPES \& MAGALHÃES, 2005).

Foi elaborado um fluxo de caixa para 10 anos (120 meses). No mês 120 somou-se à receita o valor residual de 
todo o patrimônio líquido. A viabilidade financeira dos sistemas foi analisada por meio dos indicadores de rentabilidade calculados sobre o FCL: VPL, relação B/C e TIR. O método de cálculo dos indicadores foi baseado em Noronha (1987). Os resultados econômico-financeiros foram comparados por meio de análises descritivas.

\section{RESULTADOS E DISCUSSÃO}

O uso de suplemento concentrado na fase de terminação dos cordeiros onerou financeiramente $o$ sistema com suplementação em creep feeding em R \$ 17,58 por cordeiro terminado entre os sistemas, apresentando o maior custo variável (Tabela 2). Com a utilização de área de pastagem acessória de trevo branco e cercas adicionais no sistema em creep grazing, os dispêndios com manejo da pastagem e conservação foram superiores aos demais. Os parâmetros GMD, PVF e RCQ não diferiram estatisticamente entre as estratégias de suplementação $(\mathrm{P}>0,05)$, entretanto, quando se trata de análises de viabilidade econômica a mínima diferença pode gerar efeitos monetários importantes. Assim o custo, em um primeiro momento, apresentou-se mais interessante financeiramente para $o$ manejo da pastagem em relação ao uso do alimento concentrado.

As despesas com alimentação (pasto, silagem de milho e ração concentrada) neste estudo foram as maiores contribuintes para a formação dos custos variáveis dentro de todos os sistemas, aproximadamente $38 \%$, assim como observado por Barros et al. (2009). Estudos propostos por Carvalho et al. (2006) e Santello et al. (2006) comparam sistemas de terminação de cordeiros em pasto e confinamento. No entanto, os autores não contemplaram todos os fatores de produção empregados e tampouco a manutenção do rebanho como um todo, levando em conta apenas a análise dos custos com a alimentação dos animais e durante o período de terminação. A análise incompleta dos custos de produção pode levar o produtor a tomada de decisão equivocada no momento da escolha da tecnologia a ser empregada. Por isso neste trabalho avaliaram-se os custos operacionais totais e os custos totais de produção.

Ao acrescentar aos custos variáveis os custos fixos, o creep grazing obteve o maior COT, decorrente da diferença existente entre os sistemas em relação à reserva contábil destinada a depreciação de máquinas, equipamentos $\mathrm{e}$ benfeitorias. Quando este custo não é levado em consideração no momento da elaboração das planilhas de custo, o produtor pode estar colocando em risco a atividade como um todo, pois está se descapitalizando conforme a vida útil de seus bens chega ao fim e, no momento da troca, precisará de recursos financeiros externos para repor o bem sucateado.

Outro fator de destaque neste trabalho foi a contribuição do custo de oportunidade do capital imobilizado para a formação do custo total de produção, abrangendo aproximadamente $28 \%$ dos ativos financeiros. Esse montante não deve ser compreendido como um desembolso efetivo do produtor e sim como renda implícita, onde todos os seus fatores de produção (terra, trabalho e capital) estão sendo remunerados. Quando são incluídos todos esses componentes, mesmo que o lucro seja zero, não há razões para que o produtor abandone a atividade, porque ele está recebendo pelo uso de seus próprios fatores de produção. 
Rev. Bras. Saúde Prod. Anim., Salvador, v.14, n.3, p.396-405 jul./set., 2013 http://www.rbspa.ufba.br ISSN 15199940

Tabela 2. Demonstrativo dos custos anuais (R \$ano) da produção de ovinos em pastagem de azevém anual com terminação de cordeiros em três diferentes sistemas, para módulos de 300 matrizes

\begin{tabular}{|c|c|c|c|}
\hline \multirow[b]{2}{*}{ Despesas (R\$) } & \multicolumn{3}{|c|}{ Sistemas de terminação } \\
\hline & Creep grazing & Creep feeding & $\begin{array}{c}\text { Sem } \\
\text { suplementação }\end{array}$ \\
\hline a) Alimentação concentrada (rebanho) & $12.218,53$ & $19.535,20$ & $12.218,53$ \\
\hline b) Sanidade (rebanho) & $9.959,28$ & $9.624,61$ & $12.688,82$ \\
\hline c) Aquisição de reprodutor & $1.500,00$ & $1.500,00$ & $1.500,00$ \\
\hline d) Manejo de pastagem (rebanho) & $14.879,99$ & $13.862,07$ & $13.157,22$ \\
\hline e) Assistência técnica (rebanho) & $5.098,61$ & $5.098,61$ & $5.098,61$ \\
\hline $\begin{array}{l}\text { f) Conservação de máquinas, equipamentos e } \\
\text { benfeitorias }\end{array}$ & $15.791,59$ & $10.329,71$ & $10.296,07$ \\
\hline g) Energia elétrica & 600,00 & 700,00 & 600,00 \\
\hline h) Juros sobre capital de giro & $1.072,66$ & $1.087,82$ & 986,50 \\
\hline i) Despesas gerais & 560,22 & 566,39 & 514,47 \\
\hline j) Custo variável $-\mathrm{CV}(\mathrm{a}+\mathrm{b}+\ldots+\mathrm{j})$ & $61.680,87$ & $62.304,41$ & $57.060,22$ \\
\hline $\begin{array}{l}\text { k) Depreciação de máquinas, equipamentos e } \\
\text { benfeitorias }\end{array}$ & $8.519,08$ & $6.166,34$ & $6.076,63$ \\
\hline 1) Mão de obra permanente & $12.841,80$ & $12.841,80$ & $12.841,80$ \\
\hline m) Custo fixo - CF (1+m) & $21.360,87$ & $19.008,13$ & $18.918,42$ \\
\hline n) Custo operacional total - COT $(\mathrm{k}+\mathrm{n})$ & $83.041,74$ & $81.312,54$ & $75.978,64$ \\
\hline o) Custo de oportunidade do capital imobilizado & $42.777,52$ & $34.450,45$ & $33.736,37$ \\
\hline p) Custo total de produção - CT $(\mathrm{o}+\mathrm{p})$ & $125.819,26$ & $115.762,98$ & $109.727,79$ \\
\hline \multicolumn{4}{|l|}{ *Receitas $(\mathrm{R} \$)$} \\
\hline Venda de animais para reprodução & $53.988,00$ & $53.988,00$ & $53.988,00$ \\
\hline Venda de animais de descarte & $10.488,00$ & $10.488,00$ & $10.488,00$ \\
\hline Venda de cordeiro vivo terminado & $75.341,01$ & $75.045,73$ & $77.317,09$ \\
\hline Receita total (R\$/ano) & $139.817,01$ & $139.521,73$ & $141.793,09$ \\
\hline
\end{tabular}

*Animais comercializados: 416 cordeiros vendidos vivos terminados; 74 animais jovens para reprodução (41 machos e 33 fêmeas) e animais adultos (38 ovelhas, 1 rufião e 1 reprodutor).

Fonte: dados da pesquisa.

Os demonstrativos da receita estão dispostos na Tabela 2. Os indicadores econômicos (Tabela 3) de curto prazo revelaram-se positivos para todos os sistemas estudados. Apesar do sistema em creep grazing ter tido receitas maiores que o sistema em creep feeding, agora em um segundo o momento, a utilização da suplementação com creep grazing não demonstrou ser financeiramente atrativa, pois com o elevado $\mathrm{CT}$ o resultado econômico não foi favorável a sua recomendação.

O ponto de equilíbrio é um importante indicador de escala de produção e de custeio da atividade. Nesse estudo foi considerada a venda de animais para reprodução e animais de descarte. Em cenário onde essas opções de receitas não fossem levadas em consideração o PE para os sistemas ultrapassaria os $100 \%$, ou seja, a produção de cordeiros vivos terminados não seria suficiente para suprir os custos de produção. Por exemplo, o PE para os sistemas seria: creep grazing 167\%; creep feeding $154,3 \%$; e sem suplementação $141,9 \%$. Os achados corroboram os de Barros et al. (2009) de média de $38 \%$ de contribuição da venda de animais para reprodução, remetendo a necessidade do ovinocultor brasileiro em diversificar a 
sua produção e explorar o potencial genético de seus animais.

Pelo indicador financeiro TRPL todos os sistemas apresentaram retorno financeiro à atividade. Maiores taxas foram obtidas com o sistema sem suplementação, indicando que o uso de suplementação para cordeiros não foi eficiente para acréscimos na rentabilidade em curto prazo. Neste estudo em específico vale ressaltar que os resultados econômicos obtidos para o sistema sem suplementação estão correlacionados ao bom aporte nutricional dos cordeiros e das mães, do maior PVI antes da fase da terminação e da não mortalidade de cordeiros na terminação.

Tabela 3. Demonstrativo dos resultados econômicos de curto (um ano) e longo prazo (dez anos), da produção de ovinos em pastagem de azevém anual com terminação de cordeiros em três diferentes sistemas, para módulos de 300 matrizes

\begin{tabular}{lrcc}
\hline Resultados econômicos de & \multicolumn{3}{c}{ Sistemas de terminação } \\
\cline { 2 - 4 } curto prazo (um ano) & Creep grazing & Creep feeding & Sem suplementação \\
\hline Margem bruta (R\$) & $78.136,14$ & $77.217,33$ & $84.732,88$ \\
Margem líquida (R\$) & $56.775,27$ & $58.209,20$ & $65.814,46$ \\
Resultado econômico (R\$) & $13.997,75$ & $23.758,75$ & $32.065,30$ \\
Ponto de equilíbrio (\%) & 90,00 & 83,00 & 77,40 \\
TRPL (\%) & 2,03 & 4,28 & 5,89 \\
\hline Resultados econômicos de & \multicolumn{3}{c}{} \\
ongo prazo (dez anos) & \multicolumn{3}{c}{} \\
\hline VPL & $167.141,67$ & $196.925,46$ & $254.117,35$ \\
B/C & 0,42 & 0,54 & 0,70 \\
TIR & 1,18 & 1,37 & 1,60 \\
\hline
\end{tabular}

Fonte: dados da pesquisa.

Nas análises de longo prazo (Tabela 3) o VPL foi positivo para todos os sistemas caracterizando a viabilidade dos projetos, ou seja, à taxa de desconto mensal de $0,5 \%$, a soma das receitas do período de dez anos foi superior ao investimento na atividade. $\mathrm{O}$ critério de relação $\mathrm{B} / \mathrm{C}$ é normalmente definido em termos dos valores descontados. Custos e receitas são descontados separadamente e a uma determinada taxa e se aceitam os projetos que apresentarem relação B/C maior do que um (NORONHA, 1997). As taxas de $0,5 \%$ a.m, no presente estudo, todos os sistemas não revelaram possibilidades de produzirem benefícios em excesso aos custos. A TIR deve ser igual ou superior à taxa de juros de mercado, sendo a Caderneta de Poupança a referência de comparação neste estudo; essa taxa positiva indica que o capital investido na atividade foi recuperado, e o saldo disponível a cada ano rendeu juros iguais à TIR (GUIMARÃES \& CANZIANI, 2004). No presente estudo, observou-se que os sistemas proporcionaram TIR maior que $\mathrm{o}$ mínimo desejável ( $0,5 \%$ a.m.), e o que apresentou melhor TIR foi $\mathrm{o}$ de terminação de cordeiros sem desmame.

Assim, através deste estudo é possível concluir que a alimentação foi o fator de produção que exerceu maior influência no custo variável da produção, independentemente da estratégia de suplementação; e no custo fixo, foi o custo de oportunidade do 
Rev. Bras. Saúde Prod. Anim., Salvador, v.14, n.3, p.396-405 jul./set., 2013 http://www.rbspa.ufba.br ISSN 15199940

capital imobilizado. As análises econômico-financeiras devem ser realizadas de modo que todos os fatores de produção sejam remunerados. Uma vez que essa premissa foi preconizada neste estudo, o sistema com suplementação em creep grazing não apresentou resultados econômicos superiores aos com suplementação em creep feeding.

\section{REFERÊNCIAS}

AGRAFNP. Anualpec 2010. Anuário da pecuária brasileira., 2010.

BANCHERO, G., MONTOSSI, F. Unidad experimental Ovinos. Uruguai: INIA, v.78, 1995. (Serie de Actividades de Difusión)

BARATA, P.V.A. Rentabilidade: retorno sobre investimento do ponto de vista da empresa e do empresário. Belém do Pará: Universidade Federal do Pará, 2003.

BARROS, C.S.; MONTEIROS, A.L.G.; POLI, C.E.C.; DITTRICH, J.R.; CANZIANI, J.R.F.; FERNANDES, M.A.M. Rentabilidade da produção de ovinos de corte em pastagem e em confinamento. Revista Brasileira de Zootecnia, v.38, n.11, p.2270-2279, 2009.

BRASIL. Instrução Normativa SRF ${ }^{\circ}$ 43, de 07 de maio de 1997. Dispõe sobre a apuração do imposto sobre a propriedade territorial rural e dá outras providências. Diário Oficial [da] República Federativa do Brasil. Brasília, DF, 07 mai. 1997. Disponível em: $<$ http://www.receita.fazenda.gov.br $>$ Acesso em: 10 jul. 2011.
CANZIANI, J.R.F. $O$ cálculo e a análise do custo de produção para fins de gerenciamento e tomada de decisão nas propriedades rurais. Curitiba: DERE/SCA/UFPR, 2005. 19p.

CARVALHO, S.; BROCHIER, M.; CAPPELATTI, L.; PIVATO, J. Avaliação econômica de três sistemas alimentares utilizados na terminação de cordeiros. Archivos Latinoamericanos de Producción Animal, v.14, p.86-87, 2006. Supl. 3.

COMPANHIA NACIONAL DE ABASTECIMENTO - CONAB. Custos de produção agrícola: a metodologia da CONAB. Brasília: MAPA, 2010. 60p.

GUIMARÃES, V. Di A.; CANZIANI, J.R. Análise econômica, financeira e de decisão. Curitiba: DERE/SCA/UFPR, 2004. 34 p.

HERINGER, I; CARVALHO, P.C.F. Ajuste da carga animal em experimentos em pastejo: uma nova proposta. Ciência Rural, v.32, n.4, p.675-679, 2002.

HOFFMANN, R.; ENGLER, J.J. C.; SERRANO, O.; THAME, A.C.M.; NEVES, E.M. Administração da empresa agrícola. 3.ed. São Paulo: Pioneira, 1981. 325 p.

INSTITUTO BRASILEIRO DE GEOGRAFIA E ESTATÍSTICA IBGE. Índice Nacional de preços ao consumidor. Disponível em: $<$ www.ibge.gov.br>. Acesso em: 28 nov. 2011.

LOPES, M.A.; MAGALHÃES, G.P. Análise da rentabilidade da terminação de bovinos de corte em condições de confinamento: um estudo de caso.

Arquivo Brasileiro Medicina

Veterinária Zootecnia, v.57, n.3, p.374379, 2005. 
Rev. Bras. Saúde Prod. Anim., Salvador, v.14, n.3, p.396-405 jul./set., 2013 http://www.rbspa.ufba.br ISSN 15199940

NORONHA, J.F. Projetos

agropecuários: administração

financeira, orçamentos e viabilidade econômica. 2.ed. São Paulo: Atlas, 1987. v.1, 269p.

QUADROS, D.G. Pastagens para ovinos e caprinos. In: SIMPOGECO SIMPÓSIO DO GRUPO DE ESTUDOS DE OVINOS E CAPRINOS - PASTAGENS PARA OVINOS E CAPRINOS, 2, Salvador. Anais... Salvador: UFBA, 2005. 34p.

RIBEIRO, T.M.D. Produção intensiva de cordeiros Suffolk em pastagem com ou sem desmama e comportamento seletivo de ovelhas Coopworth em pastejo. $104 p$. Tese (Doutorado em Zootecnia) - Programa de Pós-Graduação em Zootecnia, Universidade Estadual Paulista, Faculdade de Medicina Veterinária e Zootecnia, Botucatu.

SANTELLO, G.A.; MACEDO, F.A.F.; MEXIA, A.A.; SAKAGUTI, E.S.; DIAS, F.J.; PEREIRA, M.F. Característica de carcaça e análise do custo de sistemas de produção de cordeiras $1 / 2$ Dorset Santa Inês. Revista Brasileira de Zootecnia, v.35, n.4, p.1852-1859, 2006. Supl.

SECRETARIA DA AGRICULTURA E DO ABASTECIMENTO DO PARANÁ - SEAB-PR. Preços pagos pelo produtor. Trimestre: agosto-2011. Disponível em: $<$ http://www.pr.gov.br/seab/>. Acesso em: 20 set. 2011.
SILVA, C.J.A. Estratégias de suplementação e desmame precoce de cordeiros e sua influência nas características de pastagem e na produtividade animal. $113 \mathrm{p}$. Tese (Doutorado em Ciências) - Programa de Pós-Graduação em Agronomia, Universidade Federal do Paraná, Curitiba.

\section{SISTEMA FAEP. Sistema de} acompanhamento do custo de produção do leite no Paraná. Curitiba: FAEP-PR, 2005. 126 p.

SNIFFEN, C.J.;O'CONNOR, J.D.; VAN SOEST, P.J.; FOX, D.G.;

RUSSELL, J.B. A net carbohydrate and protein system for evaluation cattles diets: II Carbohydrate and protein availability. Journal of Animal Science, v.70, p.3562-3577.1992.

Data de recebimento: 08/03/2013 Data de aprovação: 13/09/2013 